\section{Combination Biologic Treatment of Refractory Psoriasis and Psoriatic Arthritis}

\section{To the Editor:}

The pathophysiology of psoriasis and psoriatic arthritis (PsA) is dependent on a multistep process that leads to chronic or recurrent inflammation ${ }^{1,2,3}$. Blockade of cytokines, receptors, and coreceptors represents one approach to treating these diseases, but a significant number of patients have a recurrent course or a persistent disease process. A persistent process appears to suggest that blockade of individual inflammatory mediators is not enough to control the disease. On the other hand, among the patients who do respond to disease-modifying antirheumatic drugs (DMARD), the doses needed to control the disease sometimes are too high and may lead to severe adverse reactions. A different or complementary approach to conventional therapy is to use combination therapy that simultaneously targets different pathogenic mechanisms of the disease pathophysiology. The rationale of using a combination of biologic agents is based upon the complex pathogenic mechanisms involved in the disease process, in which Th1 and Th17 cells play major roles. It has been shown that keratinocytes and dendritic cells in psoriatic skin overproduce interleukin 23 (IL-23), which is one of the cytokines that regulates the Th17 cells, and IL-22 induces ker-

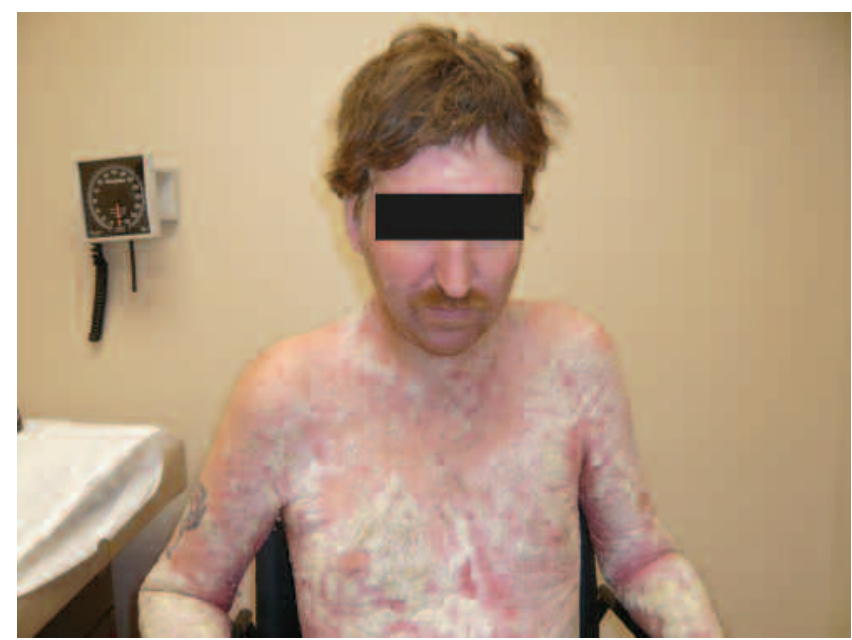

Figure 1A. Frontal view prior to combination therapy with ustekinumabetanercept showing significant emaciated appearance and extensive psoriatic skin involvement.

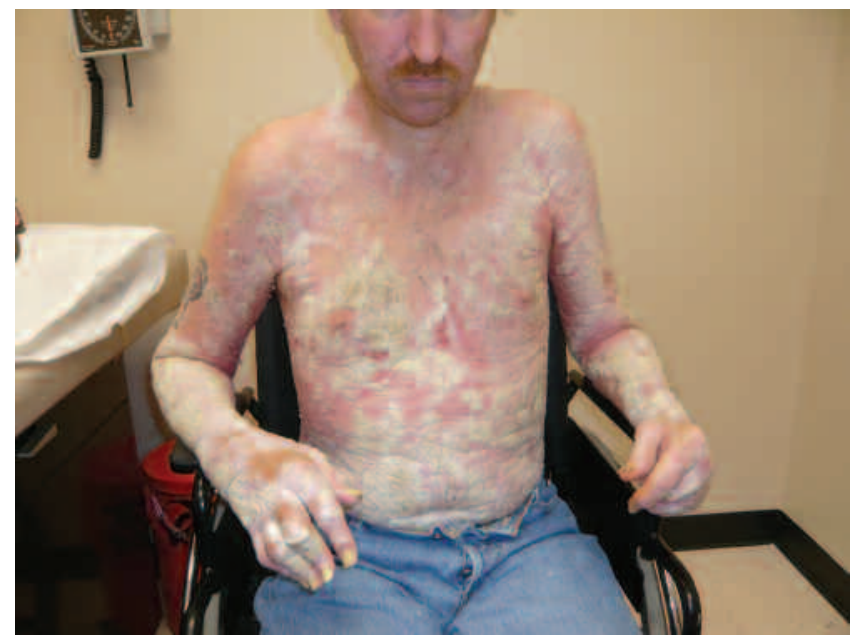

Figure 1B. Extensive skin and joint involvement prior to combination therapy. Note that patient is in a wheelchair. atinocyte proliferation. In addition, clinical data show that tumor necrosis factor- $\alpha$ (TNF- $\alpha$ ) inhibitors reduce epidermal hyperplasia as well as synovitis/enthesitis by decreasing Th1 and Th17 cell responses ${ }^{1}$.

The literature on combination biologic therapy for patients with autoimmune diseases is sparse, probably because the majority of cases are well controlled with 1 biologic agent alone or in combination with classic DMARD, and safety issues and adverse events are major concerns. We describe a patient with psoriasis and PsA refractory to standard treatment with DMARD alone or in combination with biological therapy. The patient responded to the combination of 2 biologic agents given concomitantly.

A 38-year-old white man, HLA-B27-positive, with a 20-year history of psoriasis and PsA involving peripheral and axial joints, was initially treated with topical steroids and phototherapy, with minimal skin response. He developed synovitis of small and large joints, as well as enthesitis and prolonged morning stiffness. Over the next 10 years he experienced multiple treatment regimens including nonsteroidal antiinflammatory drugs, DMARD such as methotrexate (MTX) and sulfasalazine alone or in combination with a biologic, and TNF- $\alpha$ inhibitors such as infliximab, adalimumab, and etanercept, with marginal improvement.

Because of the severity of skin involvement [body surface area 95\%; Psoriasis Area and Severity Index (PASI) 92\%], and nail, joint, and entheseal involvement, he became wheelchair-bound and unable to perform activities of daily living. Abatacept was given once a month for 18 months. At 3 months a slight beneficial effect in arthritis and skin was noted, but he was still unable to walk because of persistent synovitis and enthesitis of the right ankle. At that point etanercept was added once a week, resulting in significant joint and entheseal improvement, but still only a partial skin response. Because of the refractory skin and joint involvement, the decision was made to start ustekinumab, and the abatacept/etanercept combination was discontinued (Figure 1). This was followed within 2 to 4 weeks by significant skin and nail improvement (Figure 2). By the 4-week followup, however, the right ankle and knee had flared. Etanercept was reinitiated once a week, bringing the synovitis under control. The patient has been on this regimen for 11 months with significant improvement in the composite psoriatic disease activity index. No adverse events have occurred. He has gained $25 \mathrm{lb}$ and is able to perform most activities of daily living including hunting and fishing. Laboratory results remained within normal limits (Tables 1 and 2).

Autoimmune and malignant diseases are complex disorders of unknown etiology whose therapy remains a challenge. They may eventually require novel therapeutic approaches that combine multiple agents, each with different modes of action. Advantages of such a strategy include the ability to enhance or synergize a therapeutic response and minimize toxicities. This approach is beginning to be explored in animal models and human disorders including rheumatoid arthritis (RA) $4,5,6,7,8,9$.

The combination of 2 biologic agents given simultaneously was initially conceived in the mid-2000s for patients with RA. The rationale was that the additive and/or synergistic effects in more than 1 biological pathway may translate into clinical improvement in patients unresponsive to the traditional therapeutic regimens ${ }^{10,11,12}$.

Genovese and colleagues conducted a double-blind multicenter study

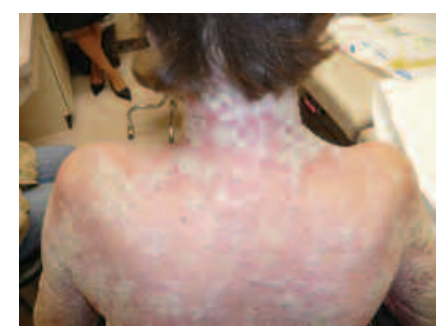

Figure 1C. Extensive scalp and back involvement prior to combination therapy. 


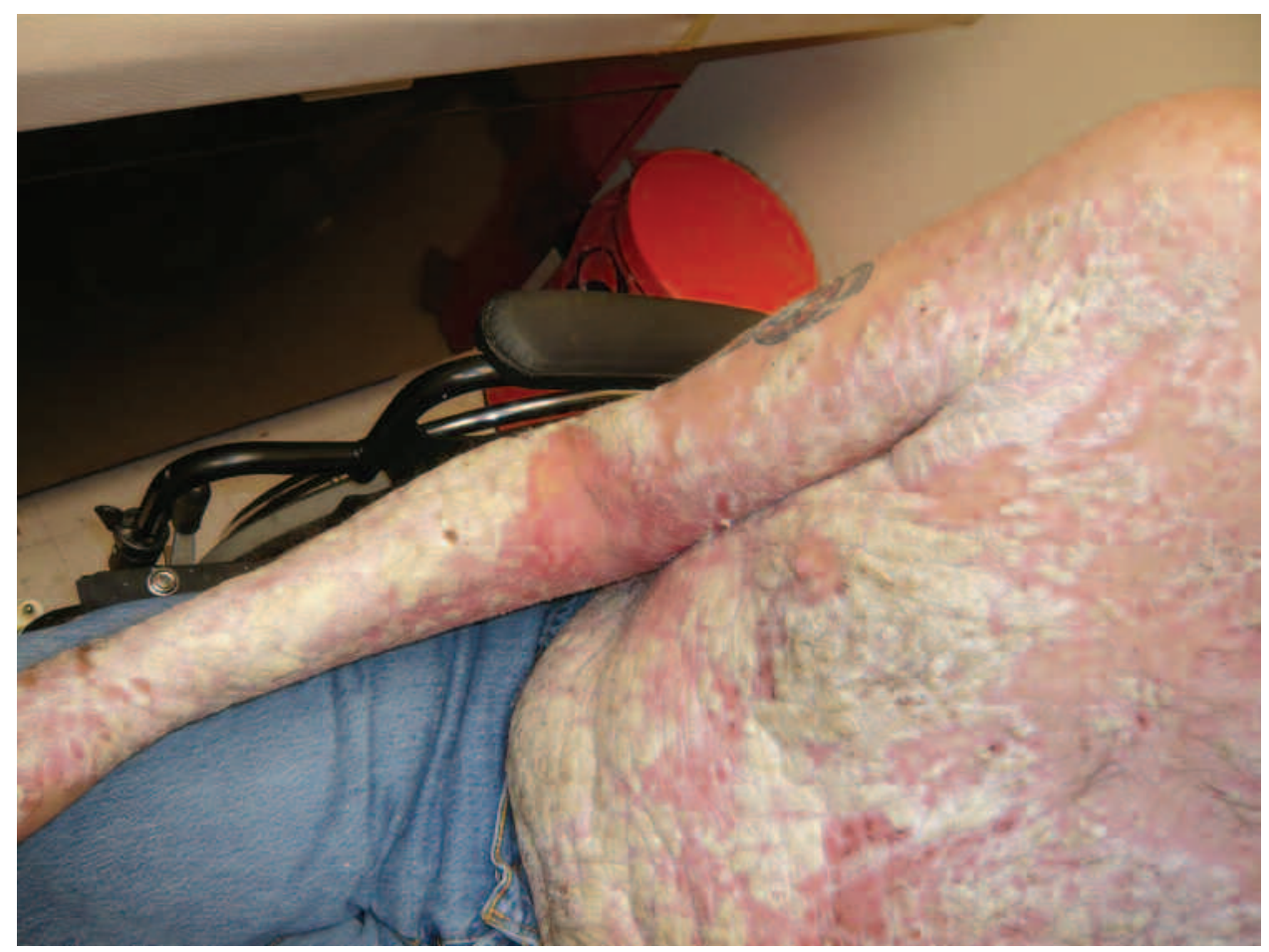

Figure $1 D$. Abdominal and right upper extremity exhibiting extensive skin involvement prior to combination therapy.

Figure 1E. Skin, joint, and nail involvement prior to combination therapy.

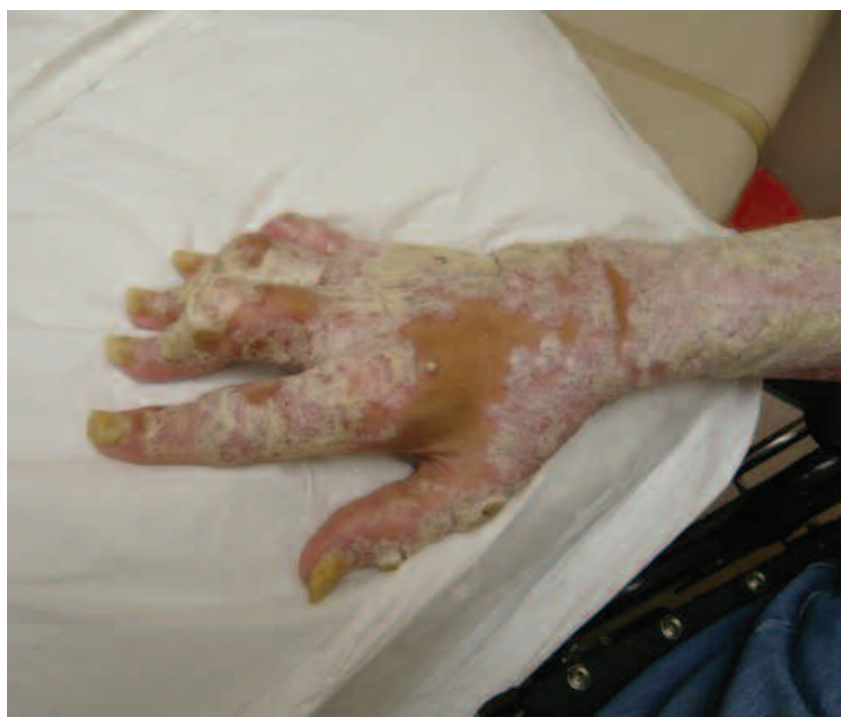

of 244 patients who had active RA despite MTX treatment ${ }^{10}$. Patients were assigned to 3 groups: etanercept $25 \mathrm{mg}$ twice weekly alone, etanercept 25 $\mathrm{mg}$ once weekly plus anakinra $100 \mathrm{mg}$ daily, and etanercept $25 \mathrm{mg}$ twice weekly plus anakinra $100 \mathrm{mg}$ daily. Patients were followed for 24 weeks ${ }^{10}$.

The hypothesis of synergistic effects was not proved and no added efficacy was demonstrated by combination therapy. Etanercept alone achieved
Figure $1 F$. Right foot exhibiting severe skin, joint, and nail involvement prior to combination therapy.

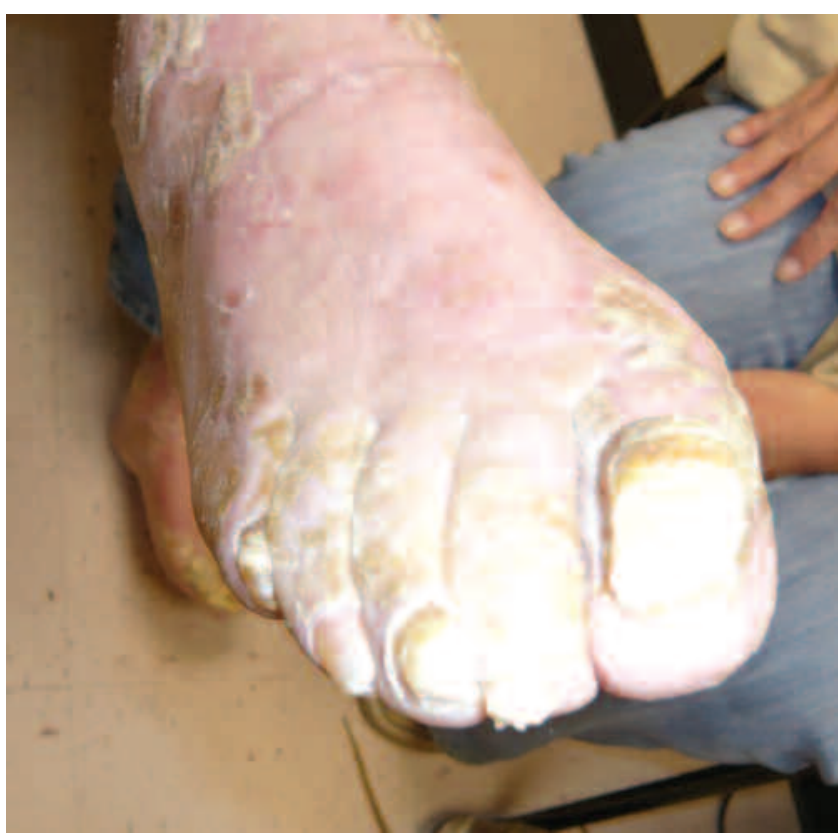

better American College of Rheumatology (ACR) 20, 50, and 70 responses, and there were few adverse events. In the combination group there was an increased rate of infections and reactions at the injection site.

Weinblatt and colleagues ${ }^{13}$ conducted a pilot phase IIb trial to evaluate the safety and clinical efficacy of abatacept $2 \mathrm{mg} / \mathrm{kg}$ plus etanercept $25 \mathrm{mg}$ twice weekly in 121 patients with active RA despite continued etanercept

\section{Personal non-commercial use only. The Journal of Rheumatology Copyright @ 2012 . All rights reserved.}



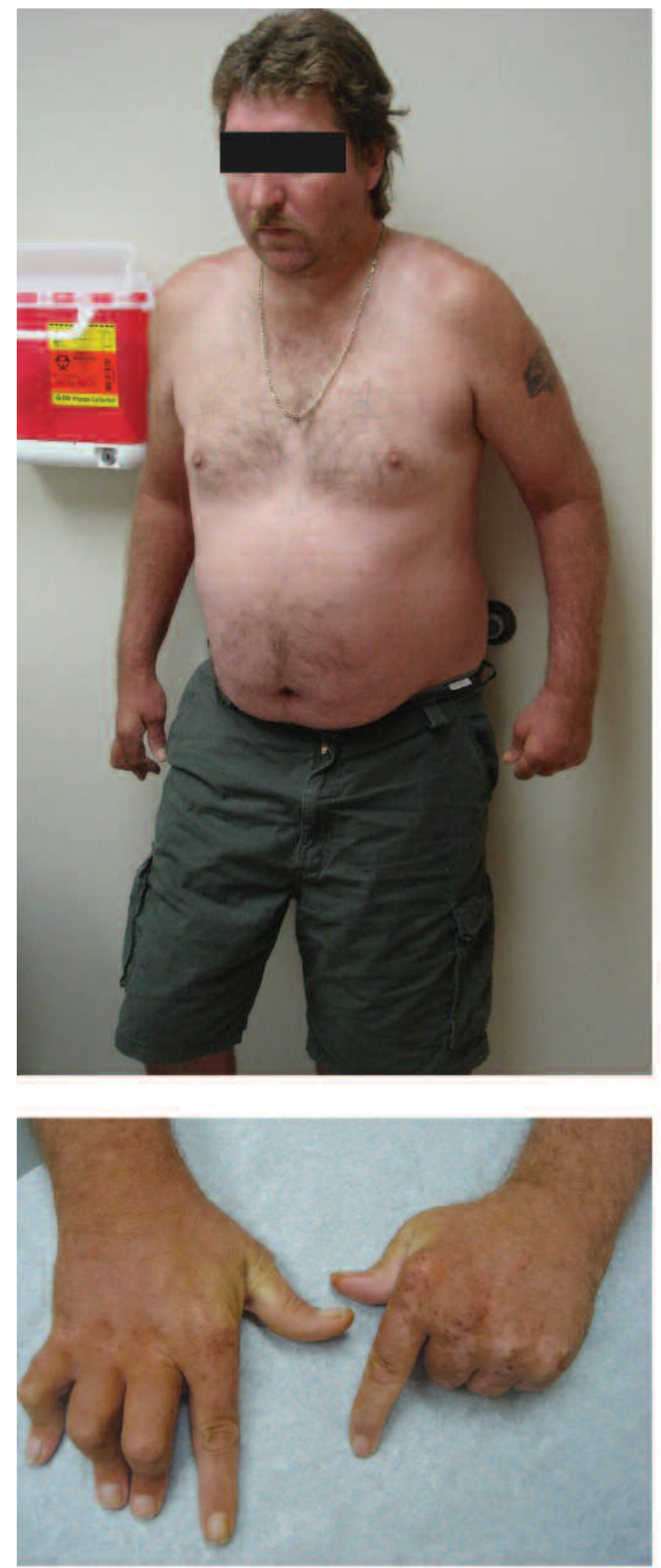

treatment. Overall results showed no significant differences between the treatment group and placebo at 6 months and at 1 year in ACR 20,50, and 70 response rates. There were no differences regarding safety at 6 months, but after 1 year there was a significant increase in the prevalence and fre-

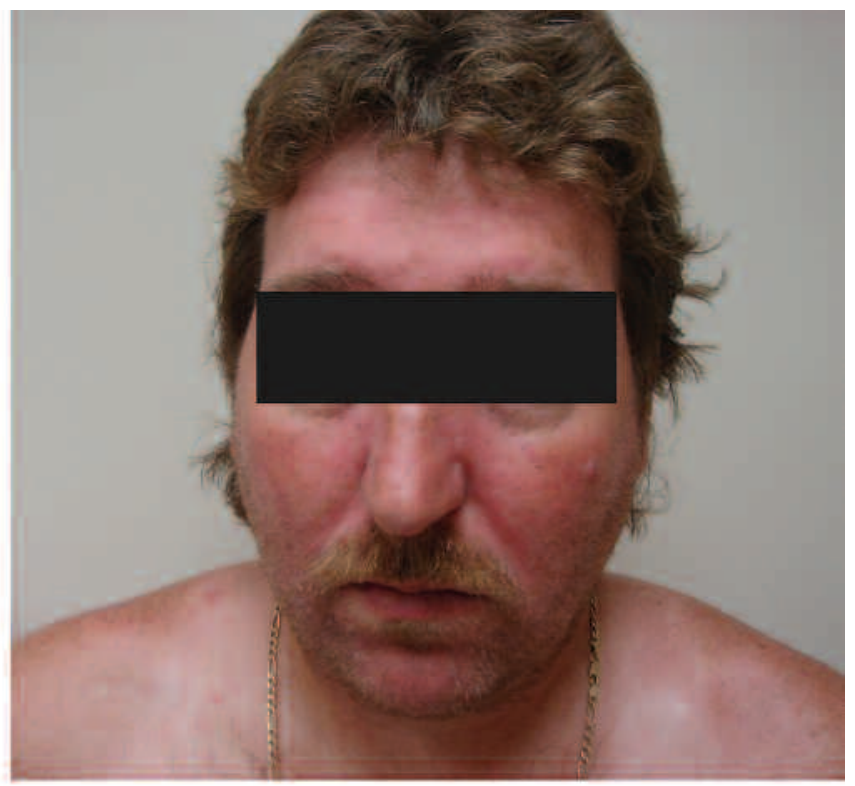

Figures 2A-2D. (A, upper left) Significant clinical improvement following combination therapy. Patient is in a standing position and has experienced significant weight gain. (B, above) Facial view following combination therapy. (C, below left) Marked improvement of psoriatic skin involvement of hands. (D, below) Disappearance of anterior chest skin involvement following combination therapy.

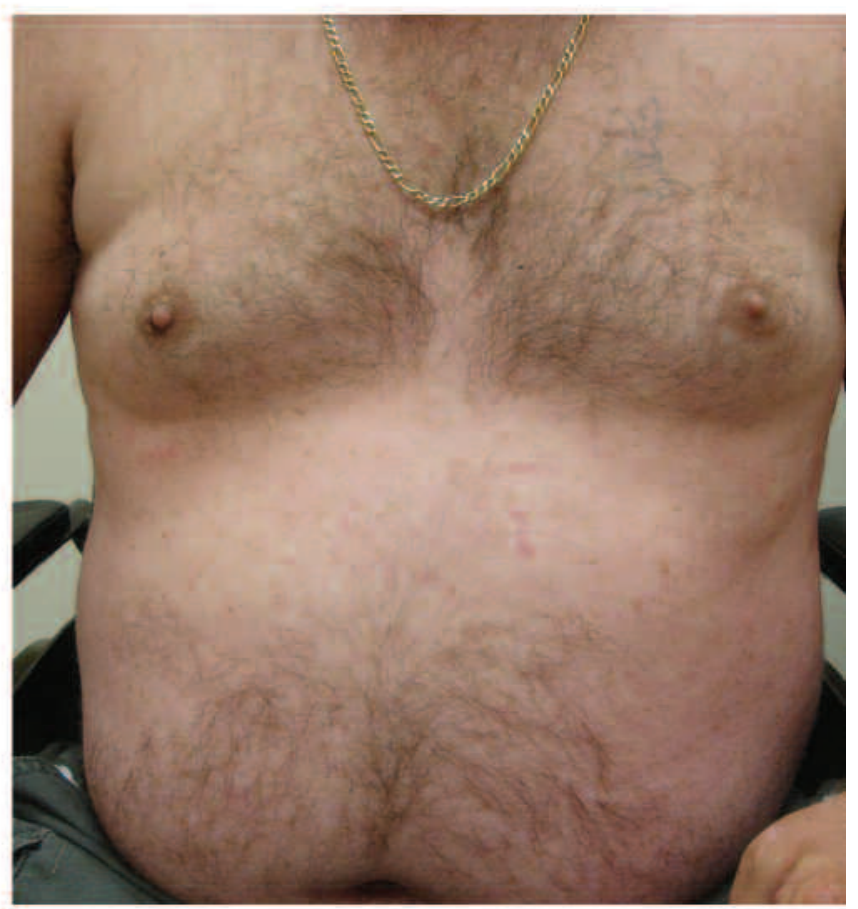

quency of serious adverse events, and combination therapy was stopped. Both Weinblatt, et $a l^{13}$ and Genovese, et al ${ }^{10}$ showed consistent results of no significant added efficacy on the primary measure (ACR response rates). Even the anakinra/etanercept trial showed a much lower efficacy

\section{Personal non-commercial use only. The Journal of Rheumatology Copyright (c) 2012. All rights reserved.}




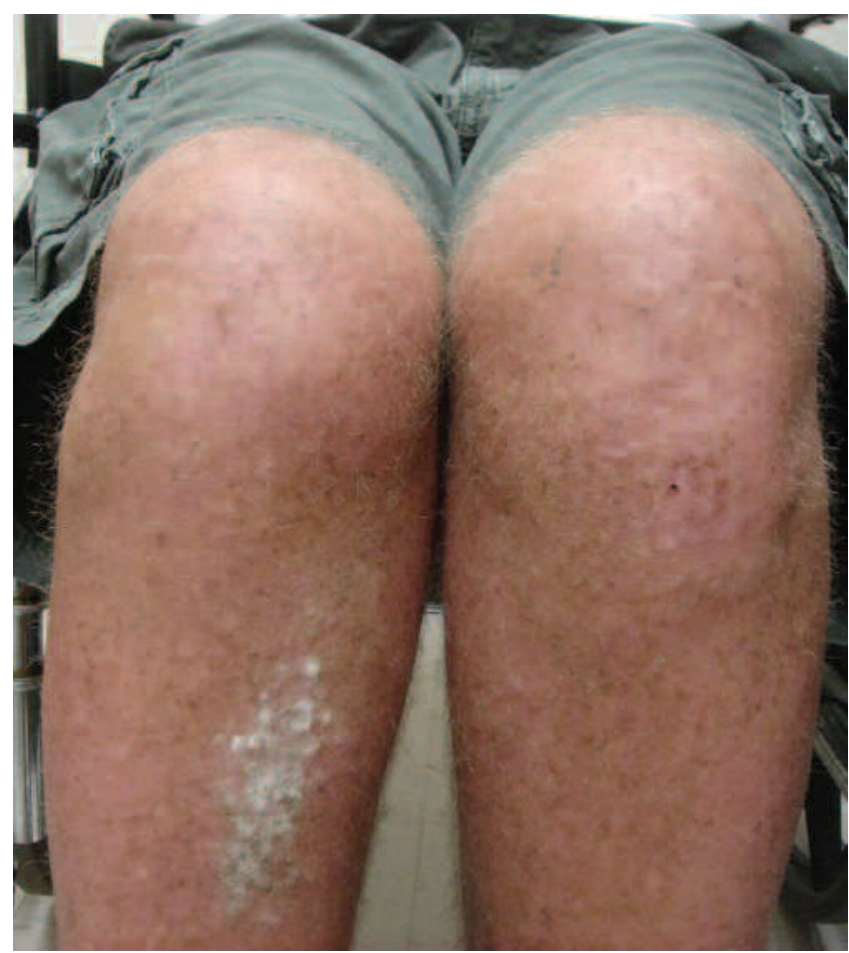

Figure 2E. Small patch of psoriasis rash on anterior aspect of right leg following combination therapy.

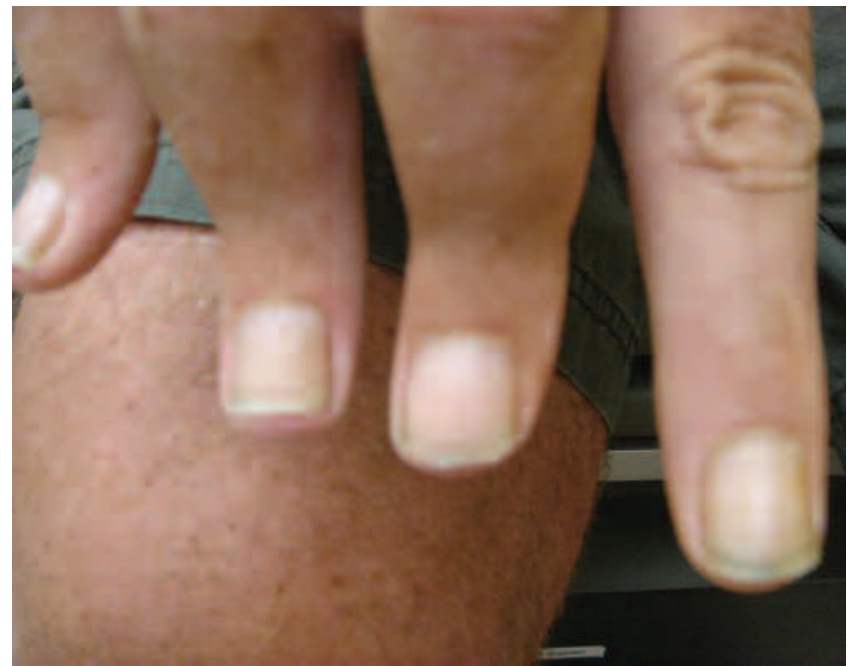

Figure 2G. Normal nail appearance following combination therapy.

when compared to etanercept alone, and there was a significant increase in safety issues, mainly infections.

Record, et $a l^{14}$ reported the first series of cases of combination therapy in patients with systemic juvenile idiopathic arthritis (sJIA), using anakinra and abatacept in 4 steroid-dependent patients with refractory sJIA, which allowed corticosteroid reduction while improving arthritis and systemic features of the disease. The patients have been followed up to 17 months and no infusion reactions or significant infections have been observed.

Recently, rituximab in combination with a TNF inhibitor and MTX was used in a group of patients with RA. There was no clear evidence of an efficacy advantage in patients receiving rituximab in combination with a TNF

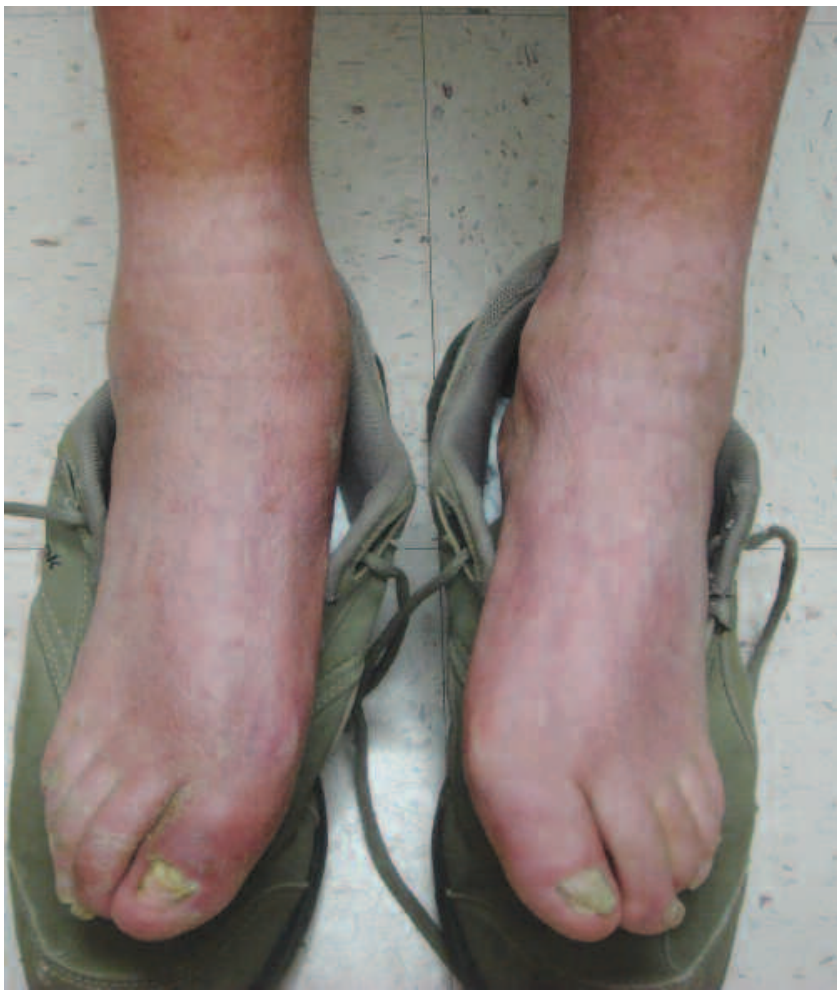

Figure $2 F$. Marked improvement of psoriatic skin, joint, and nail involvement. Note that joint deformities persist.

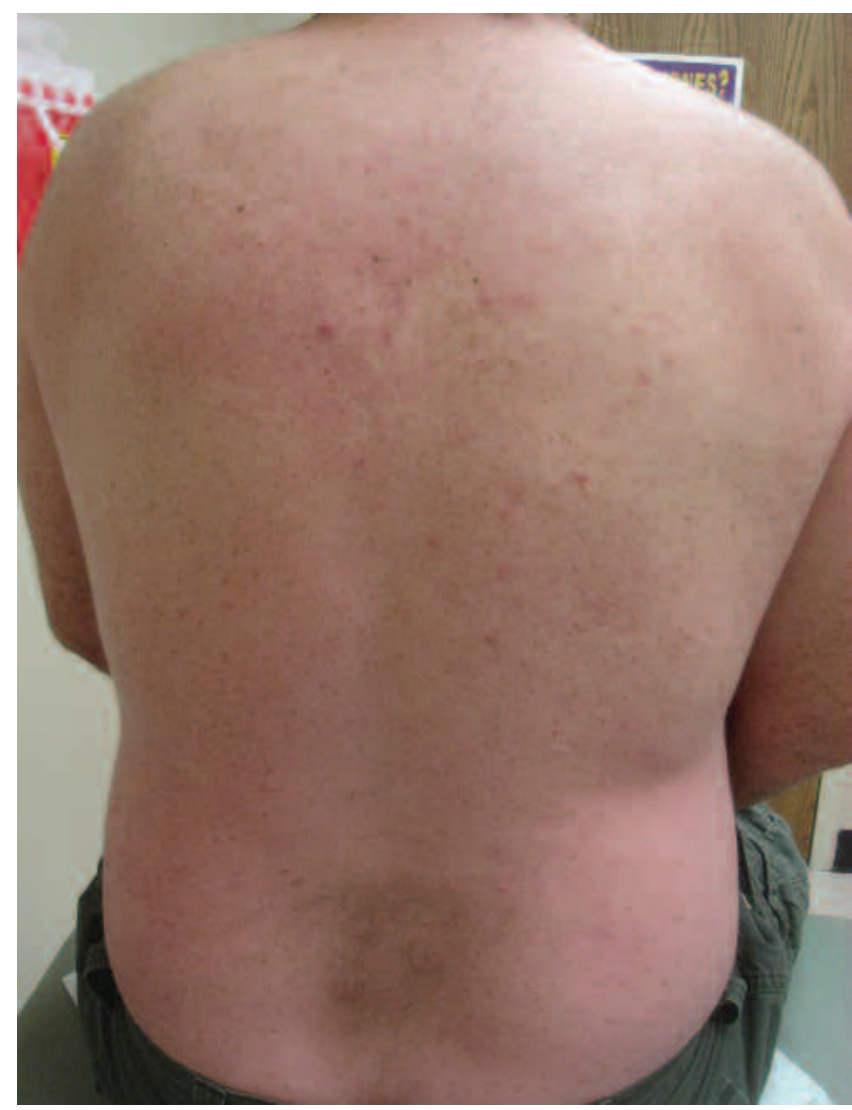

Figure $2 H$. Normal skin appearance following combination therapy.

\section{Personal non-commercial use only. The Journal of Rheumatology Copyright @ 2012 . All rights reserved.}


Table 1. Laboratory indices and Composite Psoriatic Disease Activity Index (CPDAI) scores.

\begin{tabular}{|c|c|c|c|}
\hline & June 2009 & July 2010 & January 2011 \\
\hline $\mathrm{H} / \mathrm{H}, \mathrm{g}$ per $\mathrm{dl} / \%$ & $10.7 / 34.4$ & $14.4 / 42.6$ & $14.4 / 43.5$ \\
\hline Platelets, $000 / \mu \mathrm{l}$ & 522 & 333 & 228 \\
\hline Albumin, g/l & 3.2 & 4.0 & 4.8 \\
\hline $\mathrm{ESR}, \mathrm{mm} / \mathrm{h}$ & 82 & 30 & 20 \\
\hline CRP, mg/l & 16.21 & 2.0 & 1.97 \\
\hline CPDAI & 15 & 8 & 4 \\
\hline
\end{tabular}

H/H: hemoglobin/hematocrit; ESR: erythrocyte sedimentation rate; CRP: C-reactive protein.

Table 2. Lipid profile measurements. All units of measurement are $\mathrm{mg} / \mathrm{dl}$.

\begin{tabular}{lcc}
\hline & June 2009 & January 2011 \\
\hline Triglycerides & 101 & 231 \\
Total cholesterol & 156 & 239 \\
HDL & 37 & 44 \\
LDL & 99 & 149 \\
\hline
\end{tabular}

HDL: high-density lipoprotein; LDL: low-density lipoprotein.

inhibitor and MTX. The safety profile, however, of rituximab use in combination with a TNF inhibitor and MTX was similar to the safety profile of rituximab in combination with MTX in other RA trials?.

Treatment recommendations and guidelines for psoriasis and PsA have been published in recent years, but in contrast to other autoimmune disorders, recommendations are lacking for combination biologic therapy for these conditions ${ }^{15,16,17}$.

Combination biologic therapy in severe cases of psoriasis and PsA has rarely been described (Table 3). Combination therapy for severe and/or refractory psoriasis and PsA with efalizumab plus etanercept or infliximab has been reported in 3 cases with good skin and poor joint response for efalizumab. There was good control of the synovitis but limited improvement in the skin with the TNF inhibitor ${ }^{18,19,20,21}$. In 2009 efalizumab was withdrawn from the US market because of a risk of progressive multifocal leukoencephalopathy.

Hamilton ${ }^{20}$ studied 20 patients with psoriasis and PsA who were suc- cessfully treated with a combination of efalizumab $(1 \mathrm{mg} / \mathrm{kg} / \mathrm{wk})$ and etanercept ( $25 \mathrm{mg}$ or $50 \mathrm{mg} / \mathrm{wk}$ ) or infliximab (5-6 mg/kg), with longstanding unreported serious adverse events, and effective control of both skin disease and arthritis.

There was a modest but transient improvement with the combination of abatacept and etanercept. However, eventually psoriatic skin and joint involvement became refractory to this combination biologic therapy, and ustekinumab was tried. This combination therapy has not been used in PsA, but recent reports indicate that abatacept, although effective in patients with PsA when compared to placebo, has lower response rates than those seen with anti-TNF inhibitor therapy 22,23 .

Ustekinumab is the latest biologic agent approved by the US Food and Drug Administration for the treatment of moderate to severe plaque psoriasis. It targets the p40 subunit shared by IL-12 and IL-23, preventing its interaction with the receptor and thus blocking subsequent signaling, differentiation, and cytokine production ${ }^{24}$. Both cytokines are produced mainly by activated dendritic cells. IL-12 mainly activates Th1, interferon- $\gamma$ (IFN- $\gamma$ ), TNF- $\alpha$, and cells producing IL-2, while IL-23 plays a role in the development of Th17 and IL-22, and cells producing TNF- $\alpha^{25}$. Patients with psoriasis who are treated with ustekinumab show significant improvement in histological measures of psoriasis, with minimal effect on the systemic immune response, including no changes in serum TNF- $\alpha$ concentrations ${ }^{26}$. Psoriasis response rates to ustekinumab have been shown to be the highest among biologics according to PASI response, with up to $90 \%$ response rates at Week 40 of treatment compared to an average of 50\% response rates with etanercept and other anti-TNF agents ${ }^{27}$. Preliminary data have shown that ustekinumab may also be effective in PsA, but data are not as strong as with TNF inhibitors ${ }^{28}$. Further, patient reports are beginning to be published demonstrating very good skin clinical response associated with lack of articular response in $\mathrm{PsA}^{29}$. The combination, however, of ustekinumab with etanercept in our patient proved to be highly beneficial for both skin and joint inflammation. This result suggests that combined biologic agents with different modes of action may have a role in refractory psoriasis and PsA, while maintaining a good safety profile.

Longterm combination therapy of ustekinumab and etanercept in our patient was associated with a good safety profile. Hematological indices of anemia and thrombocytosis, hypoalbuminemia, and acute-phase reactants became normal with combination therapy. Neutropenia and leukopenia were not observed. Some concern, however, should be raised over the changes observed in serum lipid levels and the development of an atherogenic lipid profile (Table 2). Patients with psoriasis have an increased cardiovascular (CV) risk, and recent evidence has shown that IL-17 may have a protective effect in the pathogenesis of the atherosclerotic process. IL-17

Table 3. Psoriasis (Ps) and psoriatic arthritis (PsA): combination biologic therapy reports.

\begin{tabular}{|c|c|c|c|c|c|c|c|}
\hline Lowes $^{18}$ & 1 & Ps & $\begin{array}{l}\text { Efalizumab }+ \\
\text { infliximab }\end{array}$ & $\begin{array}{c}125 \mathrm{mg} \mathrm{QW}+ \\
400 \mathrm{mg} \mathrm{0.2} \mathrm{Q6W}\end{array}$ & $\begin{array}{l}\text { Recurrent } \\
\text { psoriasis }\end{array}$ & $4 \mathrm{mo}$ & None \\
\hline Hamilton $^{20}$ & 20 & PsA & $\begin{array}{c}\text { Efalizumab }+ \\
\text { etanercept/infliximab }\end{array}$ & $\begin{array}{c}1 \mathrm{mg} / \mathrm{kg} \mathrm{QW}+ \\
25 / 50 \mathrm{mg} \mathrm{QW} \text { or } \\
5-6 \mathrm{mg} / \mathrm{kg}\end{array}$ & $\begin{array}{l}\text { Patients with Ps } \\
\text { and PsA }\end{array}$ & NA & None \\
\hline Kitamura $^{21}$ & 1 & PsA & $\begin{array}{c}\text { Efalizumab + } \\
\text { etanercept }\end{array}$ & $\begin{array}{l}80 \mathrm{mg} \mathrm{QW+} \\
50 \mathrm{mg} \mathrm{QW}\end{array}$ & $\begin{array}{l}\text { Recalcitrant Ps and PsA } \\
\text { unresponsive to } \\
\text { conventional treatment }\end{array}$ & $1 \mathrm{yr}$ & TB \\
\hline Cuchacovich, et al, 2011 & 1 & PsA & $\begin{array}{c}\text { Ustekinumab + } \\
\text { etanercept }\end{array}$ & $\begin{array}{l}90 \mathrm{mg} \mathrm{0.4} \mathrm{Q4W} \\
+50 \mathrm{mg} \mathrm{QW}\end{array}$ & $\begin{array}{l}\text { Ps and PsA unresponsive } \\
\text { to } 1 \text { biologic agent alone }\end{array}$ & $>1 \mathrm{yr}$ & None \\
\hline
\end{tabular}

QW: once a week; SAE: serious adverse events; TB: tuberculosis; NA: not available. 
neutralization leads to increased IFN- $\gamma$ production in atherosclerotic blood vessels $^{30}$. Ustekinumab, by downregulating IL-17, may have a negative effect on the lipid profile. In addition, briakinumab (ABT-874) is another IL-12 and IL-23 inhibitor that was recently withdrawn from further clinical studies. Its efficacy for moderate to severe psoriasis had been shown to be comparable to that of ustekinumab. However, in trials, 11 major advance $\mathrm{CV}$ events occurred at a rate of $<0.3$ events $/ 100$ patient-years in patients with 1 or fewer risk factors compared with $>2.0$ events/100 patient-years in those with 2 or more risk factors ${ }^{31}$. More recently, however, analyses of available data from phase II and III clinical trials for ustekinumab suggest neither a detrimental nor a beneficial effect of ustekinumab on serious $\mathrm{CV}$ events. Additional data are needed to define the net effect of ustekinumab on $\mathrm{CV}$ events ${ }^{32}$.

Combination biologic therapy with ustekinumab and etanercept was shown to be highly effective for our patient with refractory PsA. At the 1-year followup, combination therapy was well tolerated and was not associated with serious toxicity. The safety profile, however, needs to be closely monitored, particularly concerning CV risk, in view of the observed changes in lipid profile. The mechanism(s) of action of combination therapy remain to be fully explained. There is a need for longterm, prospective studies with larger numbers of patients in order to fully assess efficacy and the safety profile.

RAQUEL CUCHACOVICH, MD; IGNACIO GARCIA-VALLADARES, MD; LUIS R. ESPINOZA, MD, Section of Rheumatology, Department of Internal Medicine, Louisiana State University Health Sciences Center, 2020 Gravier Street, 7th Floor, Box E-20, New Orleans, LA 70112-2822, USA. Address correspondence to Dr. Espinoza;

E-mail: lespin1@1suhsc.edu

\section{REFERENCES}

1. Annunziato F, Cosmi L, Liotta F, Maggi E, Romagnani S. Type 17 helper cells - origins, features and possible roles in rheumatic diseases. Nat Rev Rheumatol 2009;5:325-31.

2. Nestle FO, Kaplan DH, Barker J. Psoriasis. N Engl J Med 2009;361:496-509.

3. Garcia-Valladares I, Espinoza LR. Psoriasis pathophysiology. Immunotherapy 2010;2:444-5.

4. Chang CJ, Chen YH, Huang KW, Cheng HW, Chan SF, Tai KF, et al. Combined GM-CSF and IL-12 gene therapy synergistically suppresses the growth of orthotopic liver tumors. Hepatology 2007; 45:746-54.

5. Perez-Gracia JL, Berraondo P, Martinez-Forero I, Alfaro C, Suarez $\mathrm{N}$, Gurpide A, et al. Clinical development of combination strategies in immunotherapy: are we ready for more than one investigational product in an early clinical trial? Immunotherapy 2009;1:845-53.

6. Huang KW, Wu HL, Lin HL, Liang PC, Chen PJ, Chen SH, et al. Combining antiangiogenic therapy with immunotherapy exerts better therapeutical effects on large tumors in a woodchuck hepatoma model. Proc Natl Acad Sci USA 2010;107:14769-74.

7. Mihara K, Yanagihara K, Takigahira M, Kitanaka A, Imai C, Bhattacharyya J, et al. Synergistic and persistent effect of T-cell immunotherapy with anti-CD19 or anti-CD38 chimeric receptor in conjunction with rituximab on B-cell non-Hodgkin lymphoma. $\mathrm{Br}$ J Haematol 2010;151:37-46.

8. Yarden Y. The biological framework: translational research from bench to clinic. Oncologist 2011;16:23-9.

9. Greenwald MW, Shery WJ, Kaine JL, Sweetser MT, Gilder K, Linnik MD. Evaluation of the safety of rituximab in combination with a tumor necrosis factor inhibitor and methotrexate in patients with active rheumatoid arthritis: Results from a randomized controlled trial. Arthritis Rheum 2001;63:622-32.

10. Genovese MC, Cohen S, Moreland L, Lium D, Robbins S, Newmark R, et al. Combination therapy with etanercept and anakinra in the treatment of patients with rheumatoid arthritis who have been treated unsuccessfully with methotrexate. Arthritis Rheum 2004;50:1412-9.

11. Bendele AM, Chlipala ES, Scherrer J, Frazier J, Sennello G, Rich WJ, et al. Combination benefit of treatment with the cytokine inhibitors interleukin-1 receptor antagonist and PEGylated soluble tumor necrosis factor receptor type I in animal models of rheumatoid arthritis. Arthritis Rheum 2000;43:2648-59.

12. Feige U, Hu YL, Gasser J, Campagnuolo G, Munyakazi L, Bolon B. Anti-interleukin-1 and anti-tumor necrosis factor-a synergistically inhibit adjuvant arthritis in Lewis rats. Cell Mol Life Sci 2000;57:1457-70.

13. Weinblatt M, Schiff M, Goldman A, Kremer J, Luggen M, Li T, et al. Selective costimulation modulation using abatacept in patients with active rheumatoid arthritis while receiving etanercept: a randomised clinical trial. Ann Rheum Dis 2007;66:228-34.

14. Record JL, Beukelman T, Cron RQ. Combination therapy of abatacept and anakinra in children with refractory systemic juvenile idiopathic arthritis: a retrospective case series. J Rheumatol 2011;38:180-1.

15. Ritchlin CT, Kavanaugh A, Gladman DD, Mease PJ, Helliwell P, Boehncke WH, et al. Treatment recommendations for psoriatic arthritis. Ann Rheum Dis 2009;68:1387-94.

16. Menter A, Korman NJ, Elmets CA, Feldman SR, Gelfand JM, Gordon KB, et al. Guidelines of care for the management of psoriasis and psoriatic arthritis: section 4. Guidelines of care for the management and treatment of psoriasis with traditional agents. J Am Acad Dermatol 2009;61:451-85.

17. Matthews JB, Staeva TP, Bernstein PL, Peakman M, von Herrath M; ITN-JDRF Type 1 Diabetes Combination Therapy Assessment Group. Developing combination immunotherapies for type 1 diabetes: recommendations from the ITN-JDRF Type 1 diabetes combination therapy assessment group. Clin Exp Immunol 2010;160:176-84.

18. Lowes MA, Turton JA, Krueger JG, Barnetson RS. Psoriasis vulgaris flare during efalizumab therapy does not preclude future use: a case series. BMC Dermatol 2005;18:5-9.

19. Adisen E, Karaca F, Gürer MA. When there is no single best biological agent: psoriasis and psoriatic arthritis in the same patient responding to different biological agents. Clin Exp Dermatol 2008;33:164-6.

20. Hamilton TK. Treatment of psoriatic arthritis and recalcitrant skin disease with combination therapy. J Drugs Dermatol 2008;7:1089-93.

21. Kitamura G, Mehr N, Anderson N, Sirichotiratana M. A case of tuberculosis in a patient on efalizumab and etanercept for treatment of refractory palmopustular psoriasis and psoriatic arthritis. Dermatol Online J 2009;15:11.

22. Mease P, Genovese MC, Gladstein G, Kivitz AJ, Ritchlin C, Tak PP, et al. Abatacept in the treatment of patients with psoriatic arthritis: results of a six-month, multicenter, randomized, double blind, placebo-controlled, phase II trial. Arthritis Rheum 2011;63:939-48.

23. Glintborg B, Ostergaard M, Dreyer L, Krogh NS, Tarp U, Hansen MS, et al. Treatment response, drug survival, and predictors thereof in 764 patients with psoriatic arthritis treated with anti tumor necrosis factor a therapy: results from the nationwide Danish DANBIO registry. Arthritis Rheum 2011;63:382-90.

24. van de Kerkhof PC. Novel biologic therapies in development targeting IL-12/IL-23. J Eur Acad Dermatol Venereol 2010;24 Suppl 6:5-9.

25. Garcia-Valladares I, Cuchacovich R, Espinoza LR. Comparative assessment of biologics in treatment of psoriasis: drug design and clinical effectiveness of ustekinumab. Drug Des Devel Ther 2011;5:41-9.

26. Reddy M, Torres G, McCormick T, Marano C, Cooper K, Yeilding Personal non-commercial use only. The Journal of Rheumatology Copyright @ 2012 . All rights reserved. 
$\mathrm{N}$, et al. Positive treatment effects of ustekinumab in psoriasis: Analysis of lesional and systemic parameters. J Dermatol 2010;33:413-25.

27. Griffiths CE, Strober BE, van de Kerkhof P, Ho V, Fidelus-Gort R, Yeilding N, et al. Comparison of ustekinumab and etanercept for moderate-to-severe psoriasis. N Engl J Med 2010;362:118-28.

28. Cuchacovich R, Espinoza LR. Ustekinumab for psoriatic arthritis. Lancet 2009;373:605-6.

29. Necas M, Vasku V. Ustekinumab in the treatment of severe rupioid psoriasis: A case report. Acta Dermatovenerol Alp Panonica Adriat 2010;19:23-7.

30. Ait-Oufella H, Herbin O, Bouaziz JD, Binder C, Mallet Z. B-cell depletion reduces the development of atherosclerosis in mice. J Exp Med 2010;207:1579-87.
31. Langley R, Papp K, Gottlieb A, Krueger G, Strober B, Williams D, et al. Long-term safety and efficacy of ABT-874 for the treatment of moderate to severe psoriasis - Interim analysis from an open-label extension study. [Internet. Accessed Aug 8, 2011.] Available from: http://www.dermatology.ca/conference/ 2010/2010Abstracts.pdf

32. Reich K, Langley RG, Lebwohl M, Szapary P, Guzzo C, Yeilding $\mathrm{N}$, et al. Cardiovascular safety in patients with moderate-to-severe psoriasis: Results of integrated analyses of data from phase II and III clinical studies. Br J Dermatol 2011;164:862-72.

J Rheumatol 2012;39:1; doi:10.3899/jrheum.110295 